\title{
PROLONGED FEBRILE ILLNESS CAUSED BY SICILIAN VIRUS INFECTION IN PORTUGAL
}

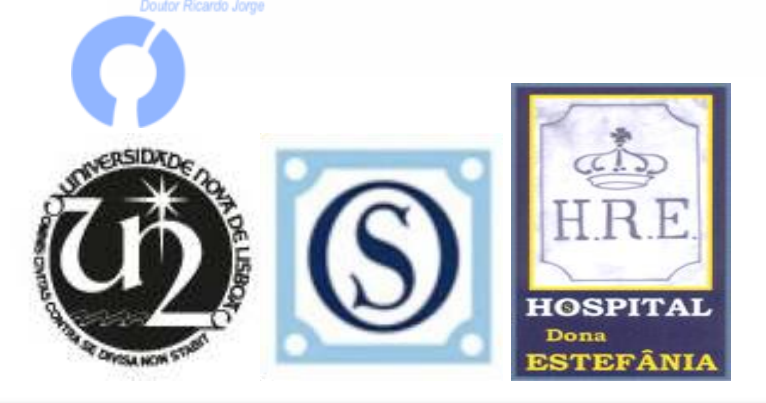

\section{INTRODUCTION}

Sandfly Fever Sicilian Virus (SFSV) is classified within the Phlebovirus genus of the Phenuiviridae family. The infection is usually seen in summer months, especially in the Mediterranean area, and causes a self-limited benign disease. The only reference to this virus concerning humans in our country was made in 1974 and was regarding antibody detection in a seroprevalence study. Since then, there are no other reports.
\end{abstract}

António Bento Guerra ${ }^{1}$, Catarina Gouveia ${ }^{1}$, Líbia Zé-Zée ${ }^{2}$, Fátima Amaro², Gonçalo Cordeiro Ferreira ${ }^{1}$, Maria João Brito $^{1}$ ${ }^{1}$ Pediatric Infectious Diseases Unit, Women, Child and Adolescents Department, Hospital de Dona Estefânia CHLC - EPE. Lisbon. Portugal

2 Nacional Institute of Health Dr. Ricardo Jorge, Centre for Vectors and Infectious Diseases Research, Águas de Moura, Portugal

\begin{tabular}{|c|c|c|}
\hline \multicolumn{3}{|c|}{ CASE PRESENTATION } \\
\hline $\begin{array}{l}\text { 8-year-old boy } \\
\text { Previously healthy }\end{array}$ & & $\begin{array}{l}\text { Owns a dog } \\
\text { avel to Ribatejo } \\
\text { (Portugal) }\end{array}$ \\
\hline $\begin{array}{l}\text { Fever }\left(39^{\circ}-38^{\circ}\right) \text { for a month } \\
\text { Malaise } \\
\text { Mild headache } \\
\text { Weight loss }(6 \%)\end{array}$ & $\begin{array}{l}\text { Skin pallor } \\
\text { Hepatosplenomegaly }(4 \mathrm{~cm}) \\
\text { Oral mucosa aphotic ulcers } \\
\text { (D3 to D7) }\end{array}$ & $\begin{array}{l}\text { Scaling hands and feet } \\
\text { (D15 to D20) }\end{array}$ \\
\hline
\end{tabular}

\section{WORKUP/ COMPLEMENTARY DIAGNOSTIC EXAMS}

\section{Microcytic anemia}

$\mathrm{Hb} 9.2 \times 10 \mathrm{~g} / \mathrm{L}, \mathrm{MCV} 74.7 \mathrm{fL}$

Leucocytes $6.8 \times 109 / \mathrm{L}$, platelets $264 \times 109 / \mathrm{L}$

C-reactive protein $65,3 \mathrm{mg} / \mathrm{L}$

Erythrocyte sedimentation rate $84 \mathrm{~mm} / \mathrm{h}$

Hypergammaglobulinemia $21800 \mathrm{~g} / \mathrm{dl}$

Antistreptolysin O titer: $664 \mathrm{UI} / \mathrm{mL} \rightarrow 1120 \mathrm{UI} / \mathrm{mL}$

Cardiologic evaluation: normal

Mouth ulcers : HSV-1 PCR positive

EBV, CMV, HIV negative; cultures negative

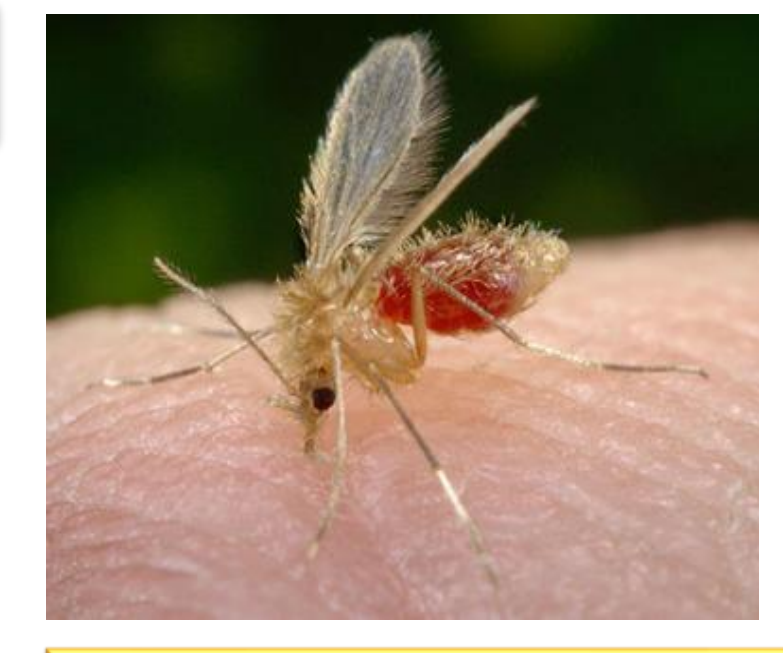

\section{Plebotomus papatasi}

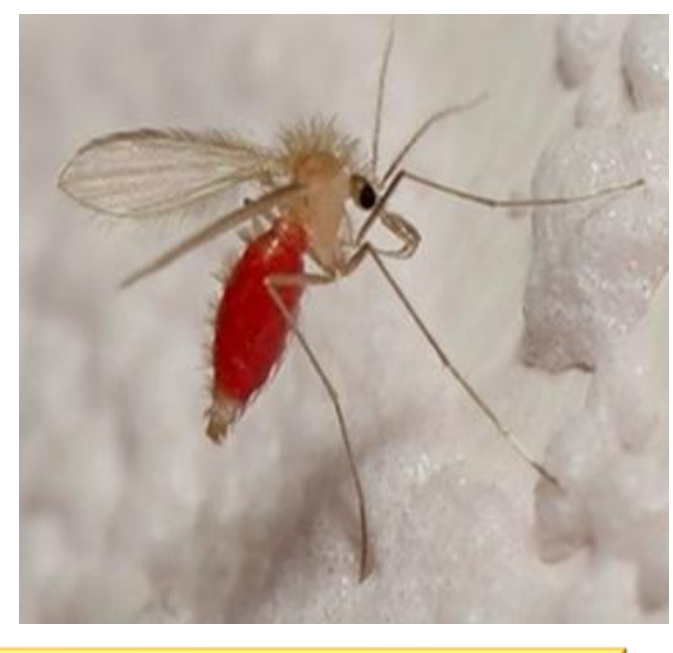

FOLLOW-UP

\section{.}

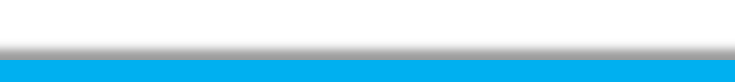
afterwards trapped specimens were negative for Phlebovirus RNA

\section{COMMENTS} never been linked to symptomatic infections

\section{for Sicilian virus positive}

Diagnosis confirmed by seroconversion

Blood SFSV molecular amplification - negative

Other causes for prolonged fever were excluded

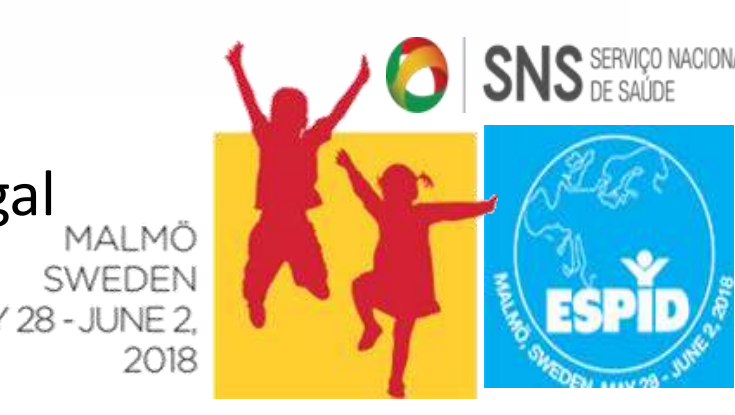

After hospital discharge he maintained asthenia and intermittent vespertine fever for one month, being clinically improved

Sandfly vector collection was performed at Ribatejo, but the two

Although in Portugal sandflies (Phlebotomus perniciosus, $P$. papatasi, $P$. ariasi, $P$. sergenti and Sergentomyia minuta) and Toscana virus CSF infections were earlier identified, SFSV has

Sandfly fever known as the three days fever may cause prolonged fever and asthenia and complete recovery may last up to 30 days

In our case we cannot exclude that other co-infections might have had a role. 